\title{
Concepções de desenvolvimento e aprendizagem em crianças com microcefalia: representações de estudantes universitários
}

\author{
Concepts of development and learning in children with microcephaly: \\ representations of university students

\section{Concepciones de desarrollo y aprendizaje en niños con microcefalia: representaciones de estudiantes universitarios}

\author{
Edna de Brito Amaral ${ }^{1}$ \\ Fauston Negreiros ${ }^{1}$ \\ Luisa Nayra Silva Gomes ${ }^{1}$ \\ Ludgleydson Fernandes Araújo ${ }^{1}$
}

Recebido em 17/05/2018; revisado e aprovado em 11/04/2019; aceito em 22/04/2019

DOI: http://dx.doi.org/10.20435/inter.v22i1.1995

\begin{abstract}
Resumo: O presente trabalho objetivou discutir as representações sociais de universitários acerca da microcefalia, do desenvolvimento e da aprendizagem. O trabalho foi realizado com 100 estudantes. Fez-se uso de uma entrevista semiestruturada analisada pelo software IRAMUTEQ. As representações perpassam a compreensão da microcefalia enquanto doença que limita o desenvolvimento e a aprendizagem. Percebe-se a necessidade de novos estudos que contribuam para a discussão mais crítica diante dessa problemática.

Palavras-chave: representações sociais; microcefalia; desenvolvimento; universitários; aprendizagem.

Abstract: The present work aimed to discuss the social representations of university students about microcephaly, development, and learning. The work was carried out with 100 students. We used a semistructured interview analyzed by IRAMUTEQ software. Representations permeate the understanding of microcephaly as a disease that limits development and learning. It is noticed the need for new studies that contribute to the most critical discussion regarding this problem.

Keywords: social representations; microcephaly; development; university students; learning.

Resumen: El presente trabajo objetivó discutir las representaciones sociales de universitarios acerca de la microcefalia, el desarrollo y el aprendizaje. El trabajo se realizó con 100 estudiantes. Se hizo uso de una entrevista semiestructurada analizada por el software IRAMUTEQ. Las representaciones atraviesan la comprensión de la microcefalia como enfermedad que limita el desarrollo y el aprendizaje. Se percibe la necesidad de nuevos estudios que contribuyan a la discusión más crítica frente a esa problemática.

Palabras claves: representaciones sociales; microcefalia; desarrollo; universitarios; aprendizaje.
\end{abstract}

\section{INTRODUÇÃO}

A microcefalia configura-se, na atualidade, como um problema de saúde pública no Brasil. Essa emergência sanitária dá-se pelo grande número de casos surgidos no país no final do ano de 2015 e início de 2016.

No último boletim divulgado, em 20 de abril de 2016, o Ministério da Saúde alertou que houve 7.150 casos suspeitos (de outubro de 2015 a abril de 2016) de microcefalia e alterações ligadas ao sistema nervoso, sendo estes sugestivos de infecção congênita. Destes, 1.168 confirmaram o diagnóstico de microcefalia, 2.241 foram descartados para o diagnóstico da doença ou mesmo de outras alterações comuns no sistema nervoso central e 3.741 continuavam ainda em investigação (BRASIL, 2016).

\footnotetext{
${ }^{1}$ Universidade Federal do Piauí (UFPI), Parnaíba, Piauí, Brasil.
} 
Cerca de 77,2\% concentram-se na região Nordeste (5.520), sendo o estado de Pernambuco aquele com maior número de notificações (760). O estado vive em situações sociais extremas, como falta de água, falta de saneamento básico, e a maioria dos partos deu-se em hospitais do SUS (97\%); outro aspecto é que a maioria das mães destas crianças encontram-se na faixa de extrema pobreza (77\%) (COSTA, 2016).

Assim sendo, o estudo aqui discorrido tem o objetivo de discutir as representações sociais de universitários acerca da microcefalia, do desenvolvimento e da aprendizagem. Diante disso, discorrer sobre essa realidade vai muito além de falar sobre um mosquito transmissor como o único responsável pelos casos de microcefalia, faz-se necessário refletir que, apesar dos avanços, o Brasil ainda apresenta problemas que precisam ser debatidos.

A microcefalia configura-se como um problema de ordem neurológica em que a circunferência craniana se apresenta menor, com 31,9cm, como no caso de meninos, e $31,5 \mathrm{~cm}$, como nas meninas. A doença é pontuada como um problema congênito e pode ser ocasionado por fatores como: "exposição de gestantes, nos primeiros meses, a substâncias nocivas"; fatores genéticos, como síndromes hereditárias; aspectos ligados à desnutrição da gestante; abuso de substanciais psicoativas e até mesmo infecção durante o período gestacional, como rubéola, citomegalovírus e toxoplasmose (SÁ, 2013; BRANCO, 2011; LUCCHESE; KANDUC, 2016; MOREIRA; OLIVEIRA, 2016; CAMARGO JR., 2016; REIS, 2015).

As consequências advindas dessa problemática são muitas, desde neurológicas a sociais, e acabam influenciando no desenvolvimento global das crianças, como neuromotor, visual, auditivo, psicossocial, relacional, e de aprendizagem, como dificuldades no processo educativo.

É pertinente discutir o aspecto da aprendizagem, entre tantas teorias, para definir esse processo, considerando a linha de análise aqui disposta, tomando por base o teórico Vygotsky (1989).

O aludido autor discute que a noção de desenvolvimento não é distinta da evolução contínua do ser humano ao longo do ciclo vital. Citando planos genéticos (filogênese, ontogênese, sociogênese e microgênese), ele procura compreender o desenvolvimento e as alterações que os indivíduos sofrem ao longo de seu processo de desenvolvimento (MOURA et al., 2016).

Analisando as implicações da teoria sociointeracionista de Vygotsky (2011) na educação, devemos considerar que um dos aspectos essenciais dessa abordagem é a noção de que os processos de desenvolvimento e de aprendizagem não coincidem e que o processo de desenvolvimento pode ser favorecido pela experiência de aprendizagem, na qual o professor é o grande mediador (CAVALCANTE, 2012, p. 91).

Nesse ponto de vista, o professor tem função primordial no processo de aprendizagem dos alunos, pois enriquece o ambiente de vivência deles com vários recursos de ensino-aprendizagem, destaca pontos importantes de um conteúdo e os envolve no ambiente de sala de aula, fazendo com que os alunos realizem atividades, de acordo com os temas de estudo, e interajam com outros estudantes e com o próprio professor na discussão de um determinado assunto.

Nesse ambiente de discussões, os alunos podem adquirir novas habilidades que os tornarão capazes de compreender novos fenômenos, em que o aluno pode vir a ser e perceber seu potencial; e, para Vygotsky (2011), o meio social aprofunda e contribui para esse desenvolvimento, junto de outros fatores.

Este estudo se constitui tendo em vista os dados citados e reconhecendo que é emergente a necessidade de se considerar o desenvolvimento e a aprendizagem em crianças que apresentam 
microcefalia, objetivando apontar quais são as Representações Sociais (RSs) de estudantes universitários acerca destes aspectos.

Aqui se reconhece a importância de abordar tais processos com enfoque na teoria das RSs, pois ela é relevante, tendo em vista que envolve níveis intrapessoal e interpessoal de análise; assim sendo, pode-se partir das representações de componentes sociais para se fazer análise das percepções em nível coletivo, que, deste modo, favorece ao pesquisador a apreensão do que é comum de uma representação (DOISE, 2001).

Como pontua Moscovici (1961), toda representação advém da necessidade que os indivíduos têm de transformar o que é estranho, incompreendido, em algo que seja familiar, esta configurandose como a premissa principal da representação. E, segundo Vala (2004), as RSs fazem uso não só das teorias científicas, mas também da vasta estrutura cultural, de sistema de conceitos formalizados, dos conhecimentos difundidos no cotidiano, bem como de diálogos presentes.

O presente trabalho problematiza quais seriam as representações sociais de estudantes universitários acerca da microcefalia, do desenvolvimento e da aprendizagem, visto que houve aumento alarmante de casos de microcefalia e que estes se configuram como um desafio emergente para a saúde pública no Brasil. Tendo em vista ser um estudo qualitativo, não se objetivaram estudantes de cursos específicos, pois acredita-se que todos os profissionais terão contato, em momentos de suas vidas profissionais, com o público de pessoas com microcefalia.

\section{PERCURSO METODOLÓGICO}

\subsection{Lócus de Investigação}

O presente estudo foi realizado em uma instituição universitária de ensino público, nas áreas comuns da instituição, como corredores, praça de alimentação e biblioteca.

\subsection{Tipo de Pesquisa}

Este estudo tem base qualitativa e não objetiva contar juízos ou sujeitos, sua base está na exploração do conjunto de ideias e representações sociais sobre o que se pretende pesquisar (MINAYO, 2010).

\subsection{Sujeitos da Pesquisa}

A pesquisa foi realizada em maio e junho de 2016, com 100 estudantes universitários de uma instituição pública de ensino superior no Piauí. Os discentes tinham média de idade de 22,5 anos, escolhidos de forma aleatória e não probabilística. Com relação ao estado civil, cerca de $90 \%$ eram solteiros, $9 \%$ casados e $1 \%$ separado.

Dos 100 universitários entrevistados, 33\% realizavam cursos na área de engenharias, 26\% na área de educação, 12\% eram mestrandos, 11\% frequentavam cursos na área da saúde e $7 \%$ faziam cursos nas áreas de ciências sociais. A renda dos pesquisados está entre menos de um salário mínimo e mais de quatro, sendo que tanto os que tinham menos de um salário mínimo quanto os que tinham de 2 a 3 salários mínimos compreenderam 31\%, respectivamente; $21 \%$ tinham renda de até um salário mínimo, 14\% tinham renda maior que quatro salários mínimos e $5 \%$ não responderam a este quesito. 
Todos os critérios éticos foram seguidos, sendo que os participantes dispuseram de livre escolha para participar ou não da presente pesquisa. Para participar da amostra, os participantes precisavam ser estudantes universitários e concordar em fazer parte da pesquisa de forma voluntária e anônima, não tendo sido verificada nenhuma resistência e/ou desistência em participar.

\subsection{Instrumentos de coletas de dados}

Os instrumentos utilizados foram um questionário e uma entrevista semiestruturada, impressos e aplicados por três entrevistadores previamente treinados, destinados à obtenção dos dados sociodemográficos, englobando idade, estado civil, escolaridade, curso e renda. A entrevista semiestruturada tinha como questão norteadora: "Para você, qual a representação sobre o desenvolvimento e a aprendizagem das crianças com microcefalia?".

\subsection{Procedimentos}

Inicialmente, foram elucidados os objetivos norteadores da pesquisa para os universitários e esclareceram-se as dúvidas que surgiram; em seguida, verificou-se a disponibilidade de participação, apresentou-se o Termo de Consentimento Livre e Esclarecido aos estudantes, em duas vias, para fins de comprovação referentes aos padrões éticos. Após isso, deu-se continuidade com a aplicação da entrevista. Pontua-se que foram seguidos todos os critérios éticos no que concerne a estudos com seres humanos, seguindo o disposto na Resolução n. 510/2016, do Conselho Nacional de Saúde (BRASIL, 2012).

\subsection{Análises de dados}

No que concerne aos dados do questionário sociodemográfico, foram utilizadas estatísticas descritivas para caracterização dos atores sociais. Posteriormente, foi utilizado o software IRAMUTEQ, que permite, por meio da "análise textual descrever um material produzido por um produtor, seja individual ou coletivamente..." (CAMARGO; JUSTOS, 2013); logo, favorece o acesso às representações sociais dos entrevistados.

Camargo e Justos (2013) enfatizam que, na análise com o IRAMUTEQ, o material é organizado em: corpus, este sendo um conjunto de escritos para serem analisados; um texto, que é referente a um conjunto de textos que formam um corpus de análise, este apropriado à análise realizada por meio da Classificação Hierárquica Descendente (Cdh1), devendo o conjunto ser um aglomerado de textos centralizado em um tema específico; segmentos de textos, que se configuram como fragmentos de escritos com extensão de três linhas, sendo formados pelo próprio IRAMUTEQ, dando-se em função da dimensão do corpus.

\section{RESULTADOS E DISCUSSÕES}

A análise dos resultados, constituída pelo corpus de 100 unidades de contexto inicial (U.C.I.), ou entrevistas, e processada pelo software IRAMUTEQ, apresentou uma divisão do corpus em 101 unidades de contexto elementar (U.C.E.), apresentando 656 palavras, vocábulos ou formas distintas, os quais ocorreram 1.950 vezes. É válido salientar que foram analisados com média de 3,97 em termos de ocorrência, sendo considerados na Classificação Hierárquica Descendente (CDH) 68,32\%. 


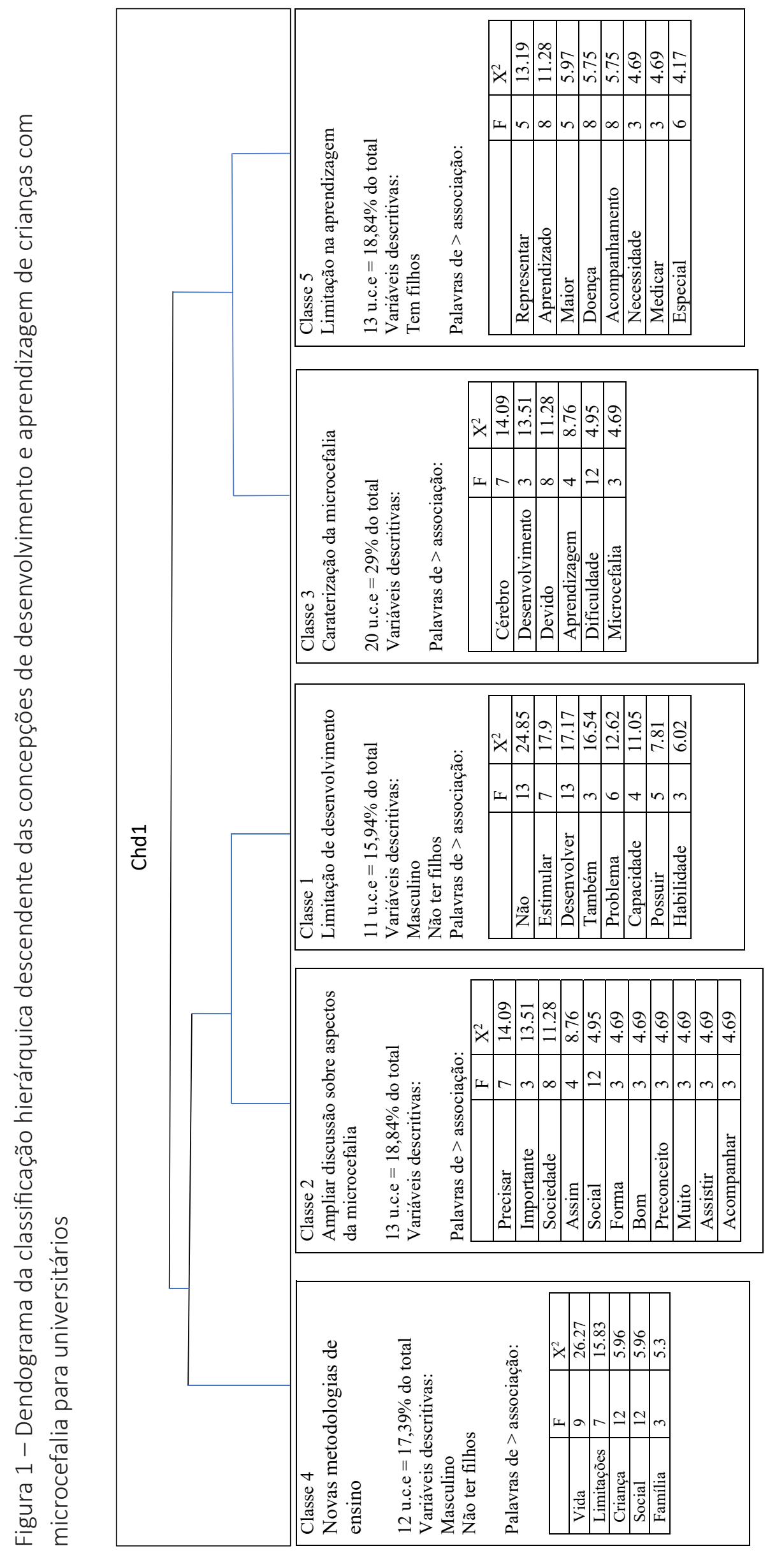

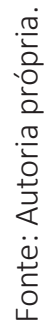


No dendograma, encontram-se descritas as cinco classes que emergiram dos discursos. Nele, observa-se que houve a formação de dois subcorpos, em que são percebidas duas subdivisões, sendo que a classe 4 surge opondo-se às classes 2 e 1 - estas surgiram interligadas entre si. No outro subcorpus, encontram-se ligadas as classes 3 e 5.

Observa-se, no referido dendograma, o título de cada uma das cinco classes, seguido pelo número de U.C.E. que compõe a descrição da classe, bem como as variáveis descritivas e as palavras de maior frequência (F) com a referida classe, levando à frequência total, bem como ao coeficiente obtido no teste de associação Qui-Quadrado $\left(X^{2}\right)$, para melhor análise alusiva às Representações Sociais (RS), optando-se por determinar quantidades específicas de palavras em cada classe, mas especificamente as de Qui-Quadrado mais significantes, com corte mínimo de 4,17, não sendo alocadas aquelas em que se analisaram valores menores ao apontado.

Após as especificações citadas anteriormente, as classes foram nomeadas da seguinte forma: Classe 1 - Limitação de desenvolvimento; Classe 2 - Ampliar discussão sobre aspectos da microcefalia; Classe 3 - Caracterização da microcefalia; Classe 4 - Novas metodologias de ensino; e Classe 5 - Limitação na aprendizagem.

\subsection{Classe 1: Limitação de desenvolvimento}

A classe 1 foi composta por 11 U.C.E, com 15,94\% de poder explicativo, tem como variáveis descritivas ser do sexo masculino e não ter filhos. Percebem-se, nos conteúdos, as palavras: não; estimular; desenvolver; problema; capacidade; habilidade.

Assim sendo, é observável que as RSs dos sujeitos refletem aspectos do desenvolvimento, porém, este sendo atravessado por pontos que precisam ser estimulados, ou mesmo a consideração dele enquanto um problema em que se precisa olhar para as capacidades e habilidades das crianças, mais especificamente as que têm microcefalia.

As crianças que apresentam microcefalia passam por muitas limitações, e faz-se necessário pensar ações que venham a criar possibilidades de atuação. Assim sendo, o Ministério da Saúde lançou documentos e protocolos que forneçam subsídios para identificação precoce e atendimento adequado às crianças com microcefalia. Outro aspecto é a garantia de um Benefício de Prestação Continuada que as famílias com renda inferior a um terço do salário mínimo terão, para cobrir o acompanhamento adequado de seus filhos (DUARTE; GARCIA, 2016).

Um aspecto que é preconizado pela estimulação precoce é uma melhor estruturação do vínculo entre a mãe e o bebê, esta enquanto possibilidade de ampliação dos vínculos familiares (BRASIL, 2016). Contudo não se pode deixar de lembrar que, apesar de existirem documentos sobre como estimular o desenvolvimento de crianças com microcefalia, estes se direcionam apenas a crianças com até 3 anos de idade.

Deste modo, e como visto no conteúdo das classes que surgiram, deve-se reconhecer que existem limitações para crianças com microcefalia, nos discursos dos entrevistados, porém estas não devem ser consideradas como permanentes, e sim como passíveis de serem trabalhadas para se tornarem menos significantes na vida destas crianças e famílias.

\subsection{Classe 2 - Ampliar discussão sobre aspectos da microcefalia}

A classe dois foi composta por 13 U.C.E, correspondendo a 18,84\% do total. Pontua-se que nela não surgiram variáveis explicativas, o que denota pouca discrepância dentro das classes, já que a maioria das classes do dendograma não apresentou variáveis explicativas. 
Pode-se observar que essas palavras, em conjunto com a análise dos conteúdos lexicais, refletem representações referentes à necessidade que os universitários têm de conhecer sobre a aprendizagem de crianças com microcefalia. Tais representações foram pautadas na necessidade de se ampliar o conhecimento que se tem acerca desse fenômeno; assim sendo, pode-se remeter que esta preocupação vem a fornecer um subsídio maior para ampliação do conhecimento. Como no discurso do sujeito 63: "Investir em tecnologia, preparar educadores direcionados para essas crianças, integrá-las à sociedade de uma forma que elas não sejam discriminadas pela sociedade".

A emergência de ampliar as discussões acerca da microcefalia dá-se pelo grande número de casos reconhecidos, e é pertinente situar, segundo Lino (2013), que os casos não se apresentam de forma homogênea. Cada caso tem suas especificidades, logo, as estratégias precisam ser diferentes para cada situação.

É válido pontuar que a necessidade de ampliação dos estudos acerca do tema deve também ser pautada na obtenção de diagnósticos mais precisos, sejam esses durante a gestação, sejam esses mesmo após o nascimento da criança, visto que só a partir de uma análise segura é que formas específicas de atuação podem ser planejadas. Outro aspecto é como tanto profissionais quanto familiares vão lidar com essas necessidades, ou mesmo com suas próprias problemáticas advindas destes casos (MESTRINER, 2016).

As discussões acerca da microcefalia fazem-se pertinentes para que se desmistifique o problema, reconhecendo que limitações existem, mas que elas não anulam a capacidade de quem as tem. As RSs sociais pontuam a necessidade de ampliação de discussões, pois demonstraram que os universitários estão buscando empoderamento para discutir a questão.

\subsection{Classe 3 - Caraterização da microcefalia}

A microcefalia configura-se como uma doença neurológica que apresenta como característica principal a diminuição da circunferência craniana, esta apresentando-se menor em comparação com demais crianças de mesma idade e sexo. Existem muitos fatores que podem ser influenciadores do surgimento da microcefalia (BRANCO, 2011; SÁ, 2013; LUCCHESE; KANDUC, 2016; MOREIRA; OLIVEIRA, 2016).

A classe 3 apresentou-se com maior peso explicativo da RS dos universitários, formada por 20 U.C.E e com 29\% de poder explicativo. As palavras referentes a seu conteúdo foram: cérebro, desenvolvimento, aprendizagem, dificuldade e microcefalia. Ou seja, observa-se que esta classe representa a percepção da microcefalia, mais especificamente quando cita o cérebro.

Dificuldade na aprendizagem ou problemas no desenvolvimento, especialmente do cérebro, danos esses prejudiciais à vida. (Entrevistado 58).

Ao meu ver, as crianças com microcefalia vão possuir problemas quanto à aprendizagem eo desenvolvimento, já que seus cérebros não se desenvolveram normalmente. (Entrevistado 70).

As características direcionadas para crianças com microcefalia apresentam-se como disseminadas pela mídia. É imprescindível pontuar que, apesar das dificuldades apresentadas por essas crianças, quando uma assistência adequada é efetuada o mais precocemente possível, um avanço significativo é proporcionado na vida delas, pois isso influenciará na qualidade de suas vidas (MOREIRA; OLIVEIRA, 2016; VENTURA et al., 2016; LÖWY, 2016).

O desenvolvimento e a aprendizagem surgem nas RSs dos universitários; logo, percebe-se a consideração de evolução das crianças com consequente necessidade de aprendizagem. Como 
dito outrora, desenvolvimento e aprendizagem não andam em paralelo (VYGOTSKY, 2011), mas andam concomitantemente.

\subsection{Classe 4 - Novas metodologias de ensino}

A classe 4 apresentou-se estruturada por 12 U.C.E, o que corresponde a 17,39\% de poder explicativo. Nesta, surgiram como variáveis descritivas ser do sexo masculino e não ter filhos. Estes aspectos dos atores da pesquisa mostram-se significativos na determinação do conteúdo da classe.

Percebe-se, nos conteúdos expressos pelos sujeitos, a consideração de metodologias de ensino para que se possa ofertar um ensino de qualidade às crianças que têm microcefalia. Neste sentido, é reconhecido que as crianças com alguma necessidade têm modos diferentes de aprender, mas que isso não é um fator limitador nem para a criança nem para a família, ou mesmo para o convívio social.

Diante das consequências biológicas relacionadas à microcefalia, e de se imaginar uma deficiência nos processos cognitivos (apesar de eu não poder afirmar com precisão), desse modo, vejo que esses processos de aquisição e formação do saber possam ser dificultados ou impossibilitados por métodos tradicionais, necessitando uma atenção diferenciada para a formação do indivíduo com microcefalia. (Entrevistado 92).

Assim sendo, remete-se que o uso de novas metodologias de ensino vem a favorecer a capacidade de aprendizagem de crianças. Segundo Gitahy, Silva e Terçario (2016), é pertinente que o professor conheça as características de desenvolvimento que seu aluno apresenta, apropriese dos estilos específicos de aprendizagem, sua história socioambiental-escolar, bem como de seus interesses e motivações; ou seja, é pertinente considerar quais seriam os recursos mais adequados que ofereceriam uma aprendizagem eficiente e eficaz.

Segundo Santos (2016), é indispensável que se compreenda a educação e os aspectos que são intrínsecos a ela. Estes seriam os pontos essenciais para se desenvolver uma ação pedagógica efetiva, sendo que, para isso, é importante que o professor procure sempre ampliar seus estudos acerca do que a literatura traz.

Observa-se, assim, que os atores da pesquisa têm, de acordo com suas RSs, uma preocupação diante da necessidade de se pensar em novas formas de ensino para as crianças que apresentam microcefalia; estes, por sua vez, já estão começando a pensar em suas atuações futuras, e tais visões críticas favorecem uma formação mais pautada na ética de sua atuação.

\subsection{Classe 5: Limitação na aprendizagem}

A classe cinco foi formada por 13 U.C.E., com 18,84 de poder explicativo. Ter filhos surgiu como variável descritiva desta classe. Observa-se que as classes 3 e 5 encontram-se diretamente relacionadas e pode-se discutir, acerca das RSs, que a microcefalia e a limitação da aprendizagem são significativas para os sujeitos entrevistados. Como no exemplo: “A aprendizagem e o desenvolvimento são mais lentos, mas é possível" (Entrevistado 65).

Discutir limitações na aprendizagem de crianças é pensar criticamente o processo de ensino, pois, como pontua Anacleto (2016), é relevante considerar o contexto dos educandos, como a questão cultural que interfere no modo de aprendizagem; considerar tais fatores é ampliar o olhar e não delimitar tudo que acontece como dificuldade ou fracasso escolar. 
Avaliar os aspectos que perpassam o ensino e a aprendizagem é considerar o contexto do aluno, sendo que esta consideração passa pelo professor, mais especificamente, pela formação que foi dada a ele, pois considera-se que a formação deve fornecer subsídios adequados e essenciais para se atuar na educação das crianças (LIMA, 2016).

Considera-se que o olhar para uma criança, independentemente da existência de limitações ou não, deve ser ampliado para a capacidade própria de cada ser (VYGOTSKY, 1989). É indispensável olhar os avanços tidos e como esses avanços aconteceram não da forma esperada, mas aconteceram, e é este ponto a se evidenciar.

Figura 2 - Nuvem de palavras sobre concepções de desenvolvimento e aprendizagem de crianças com microcefalia para universitários

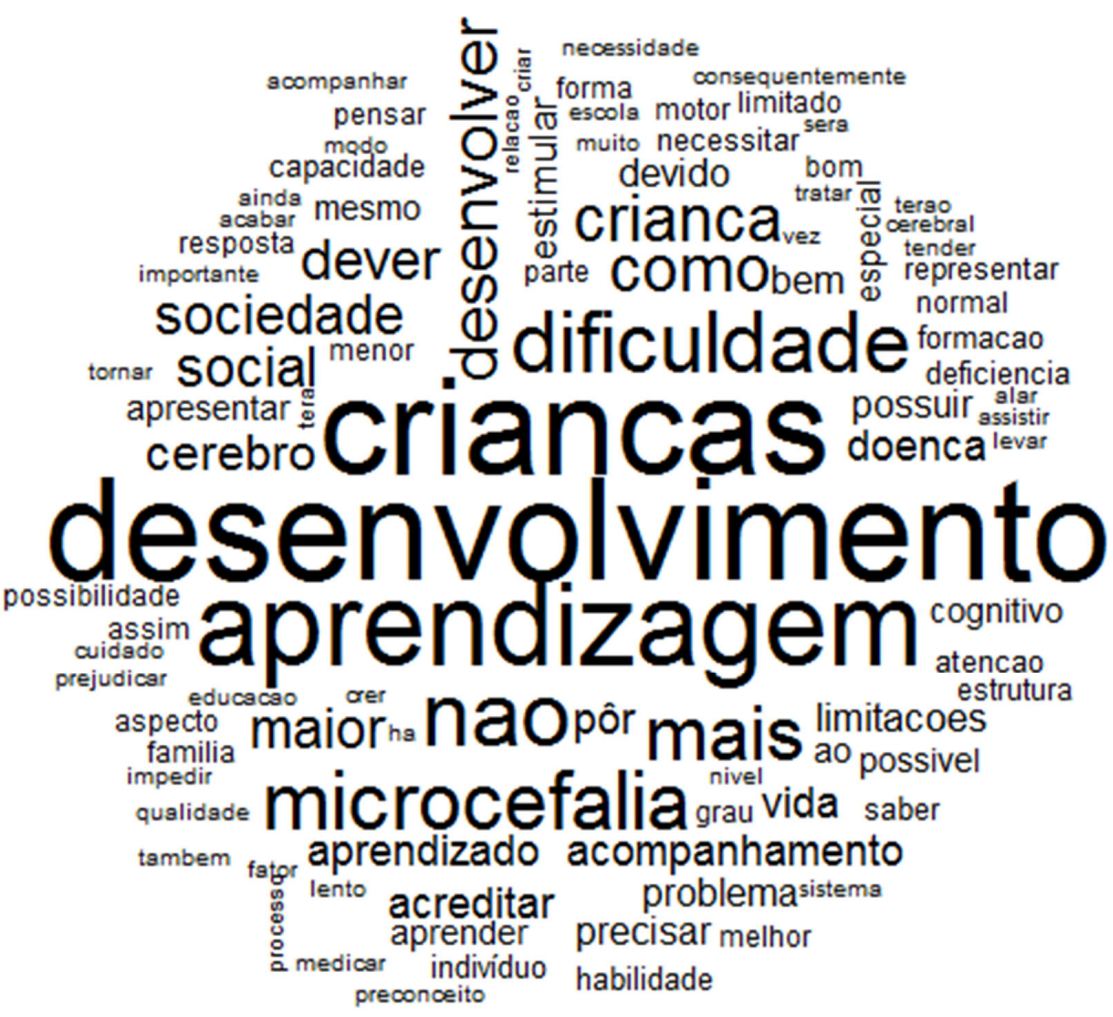

Fonte: autoria própria.

Corroborando o que se observou nas classes do dendograma, percebe-se, na nuvem de palavras, que as RSs dos universitários referem-se aos aspectos do desenvolvimento e da aprendizagem de crianças relacionados com as dificuldades decorrentes da microcefalia.

Logo, é possível inferir que existem limitações, porém não se pode deixar de pensar em formas de ensinar que venham a minimizar as possíveis dificuldades que podem surgir, a fim de assegurar o direito ao ensino e à aprendizagem de forma digna para todas as crianças, sejam essas com alguma necessidade especial ou não.

Como pontua Santos (2016), é necessário que se reinventem formas de ensinar e alfabetizar diante das demandas de nossa sociedade atual. Estas devem priorizar formas de interação das crianças com recursos que se encontram em voga no momento, como as novas tecnologias de informação, pois a interação com o meio social possibilita um aprendizado constante e as novas tecnologias proporcionam uma gama de possibilidades no campo educacional. 


\section{CONSIDERAÇÕES FINAIS}

Diante do que foi posto e dito dentro do presente trabalho, percebe-se que a representação social dos indivíduos entrevistados sobre o desenvolvimento e a aprendizagem das crianças com microcefalia reflete que eles desconheciam o potencial de desenvolvimento dessas crianças, desconheciam até a possibilidade de elas continuarem vivas após o nascimento. Os entrevistados pontuaram, ainda, a necessidade de se ampliarem as discussões sobre a microcefalia, bem como a necessidade de novas metodologias de ensino que cheguem até esses sujeitos.

Destarte se reconhece a importância de estudar, com enfoque nas RSs, assuntos que contribuam para uma discussão acerca da microcefalia relacionada ao desenvolvimento e à aprendizagem, com intuito de dar suportes que possam atender à emergência causada pelo crescimento dos índices da microcefalia.

Sabe-se que o presente estudo é preliminar, considerando o tema; contudo, espera-se poder contribuir aqui com os estudos acerca da temática, ao tempo em que se reconhece a necessidade de ampliar as discussões sobre o tema e derivar pesquisas sobre metodologias de ensino para crianças com microcefalia, de forma a estimular, ainda, linhas de pesquisas com temáticas em educação especial e sobre aprendizagem e desenvolvimento das crianças.

\section{REFERÊNCIAS}

ANACLETO, J. M. B. Relação ensino-aprendizagem e a impossibilidade da educação. Estilos da Clínica, São Paulo, v. 21, n. 1, p. 133-51, 2016.

BRANCO, N. Actividade Física Adaptada numa unidade de intervenção especializada em multideficiência. Porto: N. Branco, 2011.

BRASIL. Ministério da Saúde. Secretaria de Atenção à Saúde. Diretrizes de estimulação precoce: crianças de zero a 3 anos com atraso no desenvolvimento neuropsicomotor decorrente de microcefalia. Brasília: Ministério da Saúde, 2016.

BRASIL. Ministério da Saúde. Conselho Nacional de Saúde. Diretrizes e Normas Regulamentadoras de Pesquisas Envolvendo Seres Humanos. Brasília: Ministério da Saúde, 2012. Disponível em: http://conselho. saude.gov.br/resolucoes/2012/Reso466.pdf. Acesso em: 20 set. 2016.

CAMARGO JR., K. R. D. Zika, microcefalia, ciência e saúde coletiva. Physis, Rio de Janeiro, v. 26, n. 1, p. 9-10, 2016.

CAMARGO, B. V.; JUSTO, A. M. Tutorial para uso do software de análise textual IRAMUTEQ. Laboratório de Psicologia Social da Comunicação e Cognição (LACCOS) Florianópolis: UFSC, 2013. Disponível em: http:// www.iramuteq.org/documentation/fichiers/tutoriel-en-portugais. Acesso em: 20 set. 2016.

CAVALCANTE, A. C. S. Psicologia do desenvo/vimento e da aprendizagem. Teresina: UAB/FUEPI/NEAD, 2012.

COSTA, A. M. A determinação social da microcefalia e o saneamento. Recife: Fundação Oswaldo Cruz, 2016. Disponível em: http://scf.cpqam.fiocruz.br/eventozika/pdfs/Andre_Monteiro_Zika_ABCDE_2016. pdf.Acesso em: 20 set. 2016.

DOISE, W. Atitudes e representações sociais. In: JODELET, D. (Org). As representações sociais. Rio de Janeiro: UERJ, 2001. 
DUARTE, E.; GARCIA, L. P. Pesquisa e desenvolvimento para o enfrentamento da epidemia pelo vírus Zika e suas complicações. Epidemiologia e Serviços de Saúde, Brasília, v. 25, n. 2, p. 231-2. 2016.

GITAHY, R. R. C.; DA SILVA, J. P.; TERÇARIOL, A. A. L. O uso das tecnologias de informação e comunicação aplicadas como tecnologia assistiva na construção do conhecimento dos alunos com deficiência visual que frequentam as salas de recursos multifuncionais. Revista Ibero-Americana de Estudos em Educação, São Paulo, v. 11, n. 1, p. 111-130, 2016.

LIMA, L. A. D. Formação docente para atuação com estudantes que apresentam necessidades educacionais especiais numa perspectiva inclusiva. 2016. Monografia (Graduação em Pedagogia) - Universidade Federal do Rio Grande do Norte, Natal, RN, 2016.

LINO, J. Estratégias de integração e facilitação da aprendizagem, para alunos com microcefalia nas aulas de Educação Física: estudo de caso de uma turma. 2013. Relatório de Estágio Pedagógico desenvolvido na escola EB 2,3/S da Guia junto da Turma do 10 Ano ano letivo 2012/2013. Relatório Final (Mestrado em Ciências do Desporto e Educação Física) - Universidade de Coimbra, Coimbra, Portugal, 2013.

LÖWY, I. Zika and Microcephaly: can we learn from history? Physis: Revista de Saúde Coletiva, Rio de Janeiro, v. 26, n. 1, p. 11-21, 2016.

LUCCHESE, G.; KANDUC, D. Zika virus and autoimmunity: from microcephaly to Guillain-Barre syndrome, and beyond. Autoimmunity reviews, August, v. 5, n. 8, p. 801-08, 2016. Disponível em: https://www.ncbi. nlm.nih.gov/pubmed/27019049. Acesso em: 20 set. 2016.

MESTRINER, R. G. Uma realidade revisitada em tempos de Zika vírus e microcefalia: estamos preparados para comunicar um diagnóstico de deficiência? Ciência \& Saúde, Porto Alegre, v. 8, n. 3, p. 98, 2016.

MINAYO, M. C. S. (Org.). Pesquisa Social: teoria, método e criatividade. 29. ed. Petrópolis, RJ: Vozes, 2010.

MOURA, E. A.; MATA, M. S.; PAULINO, P. R. V.; FREITAS, A. P.; ALBERTO, C., JÚNIOR, M.; MÁRMORA, C. H. C. Os Planos Genéticos do Desenvolvimento Humano: A Contribuição de Vigotski. Revista Ciências Humanas, Taubaté, SP, v. 9, n. 1, p. 106-14, 2016.

MOREIRA, A. S. S.; OLIVEIRA, P. A. B. Infecção pelo zika vírus e malformações do sistema nervoso central. In: JORNADA CIENTÍFICA DO INTERNATO DO CURSO DE MEDICINA DO UNIFESO, 27., 2016, Teresópolis. Anais [...]. Teresópolis: UNIFESO, 2016.

MOSCOVICI, S. La psychanalyse: son image et son public. Paris: PUF, 1976. [Conforme impressão de 1961].

REIS, R. P. Aumento dos casos de microcefalia no Brasil. Revista Médica de Minas Gerais, Belo Horizonte. v. 25, n. 6, p. S88-S91, 2015.

SÁ, L. M. S. M. P. Intervenção precoce e microcefalia: estratégias de intervenção eficazes. 2013. Dissertação (Mestrado em Ciências da Educação na Especialidade de

Educação Especial no Domínio Cognitivo-Motor) - Escola Superior de Educação João de Deus, Lisboa, Portugal, 2013.

SANTOS, D. D. O processo de alfabetização nas séries iniciais do ensino fundamental: metodologias de ensino na alfabetização da criança nas séries iniciais. Monografia (Curso de Pedagogia do Centro de Educação, da Universidade Federal do Rio Grande do Norte). Nova Cruz, Rio Grande do Norte. 2016. Disponível em: http://editorarealize.com.br/revistas/fiped/trabalhos/5d814cf713d2e0dfc41684bf675e 24e7_2048.pdf. Acesso em: 20 set. 2016. 
VALA, J. Representações sociais e psicologia social do conhecimento quotidiano. In: VALA, J.; MONTEIRO, M. B. Psicologia Social. 2. ed. Lisboa: Fundação Ca., 2004. p. 457-502.

VENTURA, C. V.; MAIA, M.; BRAVO-FILHO, V.; GÓIS, L. A.; BELFORTE JR., R. Zika virus in Brazil and macular atrophy in a child with microcephaly. The Lancet, v. 387, n. 10.015, p. 228. 2016.

VYGOTSKY, L. S. O desenvolvimento dos conceitos científicos na infância. Pensamento e linguagem, 2011, p. 93-5. [Versão para eBook eBooksBrasil.com. Disponível em: www.jahr.org].

VYGOTSKY, L. S. Obras completas: fundamentos da defectologia. Tomo V. Tradução de Maria del Carmen Ponce Fernández. Ciudad de La Habana: Editorial Pueblo y Educación, 1989.

\section{Sobre os autores:}

Edna de Brito Amaral: Mestre em Sociologia pela Universidade Federal do Piauí (UFPI). Especialista em Gestão em Saúde pela Universidade Estadual do Piauí (UESPI). Psicóloga pela UFPI/Parnaíba. E-mail: ednabamaral@gmail.com, Orcid: https://orcid.org/0000-0003-0055-2553

Fauston Negreiros: Pós-Doutor em Psicologia Escolar e Educacional pela Universidade de São Paulo (USP). Doutor e mestre em Educação pela Universidade Federal do Ceará (UFC). Graduado em Psicologia pela Universidade Estadual do Piauí (UESPI). Professor associado do Programa de Pós-Graduação (Stricto Sensu) em Psicologia da UFPI. Membro da Associação Brasileira de Psicologia Escolar e Educacional (ABRAPEE).E-mail: faustonnegreiros@ufpi.edu.br, Orcid: https://orcid.org/0000-0003-2046-8463

Luisa Nayra Silva Gomes: Mestranda em Sociologia pela Universidade Estadual do Piauí (UFPI). Pedagoga pela UFPI. E-mail: luisanayra@hotmail.com, Orcid: https://orcid.org/0000-0002-2305-5798

Ludgleydson de Fernandes Araújo: Doutor em Psicologia pela Universidad de Granada (Espanha), com período sanduíche na Università di Bologna (Itália). Mestre em Psicologia e Saúde pela Universidade de Granada (Espanha), mestre em Psicologia Social e especialista em Gerontologia pela Universidade Federal da Paraíba (UFPB). Psicólogo. Professor do Programa de Pós-Graduação em Sociologia (Stricto Sensu) e do Departamento de Psicologia da Universidade Federal do Piauí (UFPI). E-mail: ludgleydson@gmail.com, Orcid: https://orcid.org/0000-0003-4486-7565 